\title{
Loot boxes as a form of gambling, and their potential for contributing to gaming related harm
}

\author{
Mike Dixon and Chanel Larche
}

This non-peer reviewed entry is published as part of the Critical Gambling Studies Blog. Visit an interactive version of this blog at: https://criticalgamblingstudies.blogspot.com/2021/04/loot-

boxes-as-form-of-gambling-and.html

There is something extremely compelling about opening a box when the contents within it are unknown. From depictions of treasure chests in pirate movies to children who can barely contain their excitement on Christmas morning, the appeal seems almost universal. The gaming industry has tapped into this appeal. They go by different names: mystery boxes, treasure chests, or most commonly, loot boxes. Loot boxes take many forms - some can be earned through successful play, or they can be bought with real money in a process called a 'microtransaction'. Loot boxes are immensely popular. Zendle, Ballou and Meyer (2019) note that over $70 \%$ of games played on Steam (a videogame distribution platform where players buy, play and discuss games) contain loot boxes. Whereas developers used to depend on players spending say $\$ 60$ for a new release, now there are free-to-download games with game designers being financially compensated solely by microtransactions. This relatively new business model is exceedingly successful. In 2018, such microtransactions generated $\$ 30$ billion in sales with projections rising to $\$ 50$ billion by 2022 .

Loot boxes have generated much controversy. Regulators in China, Japan, Belgium, and the Netherlands believe they are a form of gambling. They see paying for loot boxes as akin to wagering on a slot machine. You pay to open a box hoping to get something good, but like a slot machine, the outcome is unknown and the odds of getting something desirable are small.

The effects on some gamers read like testimonies from problem gamblers. An anonymous Reddit post reads 'When your brain works like mine, you can't stop. There is always the little voice of the back of your head that goes "Yeah no man, you should've quit like 30 boxes ago", but even when you're telling yourself to stop, you're still clicking buy, and you're still opening boxes'. Heather Alexandra writes, 'To some, loot boxes may be a gameplay issue or a consumerist concern. To me, they're far more seriously a moral issue. I know, because I have fallen for them. I don't know how else to say this, but I have a gambling problem. I didn't find this out at a casino. I found this out playing games'. 


\section{Critical Gambling Studies Blog}

In this blogpost, we will discuss some issues with which regulators are grappling, some research that links loot box purchases to problematic gambling, and gaming related 'harms' that may be linked to loot boxes.

Mark Griffiths is one of the most prolific gambling researchers. He considers gambling to have the following hallmarks: ' (1) the exchange is determined by a future event for which, at the time of staking money (or something of financial value), the outcome is unknown; (2) the result is determined (at least partly or wholly) by chance; (3) the re-allocation of wealth (i.e., the exchange of money [or something of financial value] usually without the introduction of productive work on either side); and (4) losses incurred can be avoided by simply not taking part in the activity in the first place' (Griffiths, 2018).

For loot boxes purchased via a microtransaction, there is a staking of money. What you get is usually determined by chance (and as with slot machines, the odds or payback percentage are typically unknown to the player). These first two hallmarks are unequivocally shared by loot boxes and spins on a slot machine. Legal arguments have ensued over whether there is reallocation of wealth - with the gaming industry arguing that the items in a loot box only have value within the context of the game. For example, many loot boxes contain only cosmetic items called 'skins' that game creators suggest have no monetary value - you cannot cash out a skin within the game for money. For at least some games, however, payment for a rare skin may be only a few clicks away. There are on-line markets that buy and sell skins - thus a player could, theoretically, open a loot box, find an exceedingly rare skin and sell that skin for far more than they paid for the loot box.

Some of the legal arguments lie, not on whether skins can be exchanged for money, but how they can be exchanged for money. In slots when one cashes out, the player's balance is printed out by the slot machine - the player walks to the cashier area and exchanges the printed ticket for cash. Thus, cash in and cash out are transactions overseen within the casino. For loot boxes, the players purchase the skins within the game but to redeem the value of the loot box's contents players must exit the game and go to $3^{\text {rd }}$ party sites not controlled by the game. In the UK, this distinction was salient enough for loot boxes not to fall under gambling regulations.

Thus, one view is that the game designers are not at fault since they are at arms' length from the translation of skins into cash. From the players perspective presumably, the rewarding value of the rare skin is equally reinforcing regardless of where they redeem the money. Critics also argue that without the game, there are no skins, and without the skins the marketplaces would not exist.

Research suggests that focusing on whether or not loot box items can be translated back into cash may be peripheral to the potential harms imposed by loot boxes. Research by Zendle, Meyer, and Over (2019) polled over 400 adolescents about why they have purchased loot boxes. Crucially less than $1 \%$ of the sample cited making money from loot box items. This contrasts 


\section{Critical Gambling Studies Blog}

with more traditional forms of gambling, where viewing gambling as a way to make money is associated with gambling problems. For these adolescents, a far more compelling reason for purchasing loot boxes is the thrill of opening the loot box itself. This thrill may have many components. First there is the aforementioned universal appeal of the unknown. Loot box designers have designed loot boxes to ramp up the anticipatory excitement using effective audiovisual cues. We have documented that players watching such loot boxes being opened show significant increases in physiological arousal in the anticipatory period prior to the loot box being opened (Larche et al., 2020). The designers of the loot boxes use a slots-like, random element to determine the prizes to be won. They are programmed so only very rarely will players open a loot box with a rare item that they value (i.e., akin to the rarity of large wins in slots). Mostly they will receive common items of little value - with the awarding of the prizes delivered on an intermittent random reinforcement schedule. In Zendle et al.'s study some adolescents reported buying loot boxes to get the 'gambling feeling' that comes with opening them.

Those representing the gaming industry view loot boxes as a harmless activity akin to collecting sports or other memorabilia cards. You pay to purchase a pack of cards whose contents are unknown. You hope there will be cards you value (favourite players, non-duplicates, etc.). They argue that what makes loot boxes different from plays on a slot machine is that you always get something - maybe not the items you want, but you always get something. By contrast, in slots, the most frequent outcome of a spin is the loss of the player's entire spin wager. That is, unlike loot boxes, you can bet on a spin and get nothing back.

It is of interest to push this line of reasoning that loot-boxes are not gambling because 'you always get something'. We have obtained the programming documents for modern multiline slot machines (Harrigan \& Dixon, 2009). These programming documents reveal that although full losses are the most frequent outcome, the next most frequent outcome are losses disguised as wins (LDWs). Here the player bets say 10 cents on each of 20 lines for a spin bet of $\$ 2.00$ and gets back say 20 cents. On these LDW outcomes, the player 'gets something' but certainly not what they wanted, much like the gamer who gets three common, low value items when they open the loot box. By the logic that loot-boxes are not gambling because 'you always get something', would LDWs not be considered a gambling outcome?

Consider also the 'bonus features' that are interleaved into regular slot machine play. Like the loot box, they are infrequent, yet very exciting events that are highly motivating to players. For example, in the popular game Lucky Larry's Lobstermania entering the classic bonus round triggers a game feature where players are shown a fisherman hauling in lobsters of various sizes - the bigger the lobster the more credits they are worth. In these bonus rounds the player always wins something - it could be a little or it could be a lot. Again, it would be hard to argue that because the 'player always gets something' that these bonus features should not be considered gambling. 


\section{Critical Gambling Studies Blog}

In gambling research, gambling related arousal is a crucial, if not the crucial reinforcer of gambling behaviour (e.g., Brown, 1986). To the gaming industry much has been made of how loot boxes often contain items that are purely cosmetic - they do not improve the skill of the player, only the appearance of the player's avatar or their weaponry. As such the tacit reasoning goes, how valuable, and hence how harmful can they be?

The key to the appeal of loot boxes containing cosmetic skins appears to depend on the rarity of the items in the loot box. Indeed the excitement of opening loot boxes with rare items is such that players even get a vicarious thrill from watching others open a box. This YouTube video of loot-box openings from the popular game Overwatch has been viewed over 1.8 million times!

We showed these videos to avid Overwatch players and recorded their subjective and objective reactions. In Overwatch, the contents of loot boxes are categorized according to their rarity - in the videos there are rare items, even rarer items (referred to as 'epic' items) and the rarest items (so-called 'legendary items'). We showed that players' subjective and physiological arousal scaled up with the item's rarity, with legendary items triggering the greatest arousal. Importantly players' urge to open more loot boxes also scaled up with their rarity. Finally, we used a measure from the gambling literature called the post reinforcement pause (PRP) to gauge how rewarding these different types of items were. In slots, when players spin and lose, they tend to initiate the next spin quickly. When they spin and win, they tend to pause, as though to internally celebrate the win - the bigger the win, the longer the pause (e.g., Dixon et al., 2019). The PRPs to the loot box openings was eerily similar to the pattern of pauses shown by slots players. The rarer the items in the loot box, the longer they paused to internally celebrate these items.

In sum, even though these items were purely cosmetic, players showed measurable increases in arousal depending on how rare the items were. Importantly, these reactions were measures of vicarious thrill. It stands to reason that had we measured players' reactions to opening their own loot boxes, players' reactions would likely be amplified. This study shows that players react to loot boxes in ways that are very similar to slot machine outcomes. In both games, players show excitement-linked arousal to the rarest outcomes ('legendary' items in Overwatch loot-boxes, big wins in slots).

The arguments above suggest that there are important parallels between loot boxes and slot machines. There are studies that suggest that slot machines are associated with greater gambling harm than other types of gambling (e.g., Delfabbro et al., 2020). Importantly research also suggests that loot boxes are associated with gambling harm.

Zendle and Cairns (2018) in a large-scale survey of over 7000 gamers found evidence for a link between the amount that gamers spent on loot boxes and the severity of their problem gambling measured using the Problem Gambling Severity Index (PGSI). This link was stronger in 


\section{Critical Gambling Studies Blog}

terms of effect size $(\eta 2=0.054)$ than other traditional correlates of problem gambling like depression. Importantly this link was also stronger than the association between problem gambling and simply buying in-game items when sales did not involve the loot-box format $(\eta 2=0.004)$. Thus, it is the gambling-like features of loot boxes that the authors deemed crucial in the loot-box-spending -problem-gambling link.

While this study polled adults, Zendle, Meyers and Over (2019) conducted a similar study on 16 to 18 year-olds. They again found a link between loot box spending and gambling problems, but the effect size of the association ( $\eta 2=0.12$ ) was more than twice as large as with the adult sample. This link between loot box spending and gambling problems among adolescent loot box users has since been replicated (Kristiansen \& Severin, 2020), suggesting that those in age groups where frontal lobe capacities are still developing may be particularly at risk for development of gambling problems arising from loot box purchasing.

\section{Some conjectures about general harm associated with loot boxes}

Understandably, parents may be less concerned about legal definitions of gambling, compared to whether loot-boxes may be harmful to their children. As aforementioned, loot boxes are designed to be exciting. Part of their allure is their unpredictability - one never knows whether the contents within the loot boxes will be so common as to be considered worthless by the player or so rare that they are considered extremely valuable. The reinforcement schedule of loot boxes appears to mimic the random ratio reinforcement schedule used by slot machines. In some games, players have the choice to pay for loot boxes with a microtransaction or they can earn loot boxes by successful play. At first glance it would seem that those who choose to earn rather than buy their loot boxes can avoid the problems documented by Zendle's group. One of the hallmarks of problematic play, however, in both the slots domain, and in videogaming, involves playing to escape. In both situations certain players experience a state of immersion that we call dark flow - an experience of total immersion in the game, distortions in the passage of time, and importantly, positive affect (e.g., Dixon et al., 2018). Some players appear to play slots, or videogames as a maladaptive coping mechanism to deal with negative aspects in their daily lives. They may be depressed, or bored, and elevate their mood via the flow that is induced by the attention-capturing aspects of slots or video game play. While slots outcomes are determined purely by chance, success in video game play depends in part on skill. We have shown that skill impacts the degree of flow experienced - the more skill, the greater flow, the greater flow, the more positive affect (Larche $\&$ Dixon, 2020). We have also shown that those who endorse playing video games to escape experience greater flow than those who play video games for other reasons (Larche et al., 2020). Importantly these players also score higher on measures of problematic game play. Thus, if players are attracted by the gambling-like nature of loot boxes, and the only way of getting loot boxes other than paying for them is to earn them through leveling up, this will set up a situation where 1) their skill will improve, 2) their 


\section{Critical Gambling Studies Blog}

experience of (dark) flow will intensify, 3) their positive affect during play will be elevated. For players with problems in everyday life, such games may be especially appealing because they are a forum where their mood becomes elevated. Such coping mechanisms will incur costs in terms of too much time devoted to video games and less time available for school work, relationships, etc.

The link between skill, flow and positive affect has implications for games in which loot boxes contain features that actually improve players' skill. Indeed, in Zendle et al.'s study with adolescents, the most often cited motivation for purchasing loot boxes was to accrue game-play advantages. Thus, if loot box items improve players' skill, and greater skill is linked to greater flow, then loot boxes with items that confer game play advantages may be particularly alluring to those who game to escape and theoretically could contribute to gaming harm.

The amount of time spent playing video games among teens is somewhat shocking. A poll of U.S. parents of teens indicated that $41 \%$ of 13 -to- 18 -year-old boys played every day ( $20 \%$ for girls). Among boys that play every day, over $50 \%$ of them spend three hours a day or more! Such time expenditures, and the link to dark flow are two aspects that really stretch the analogy between loot boxes and card collecting. We cannot imagine that even the most avid Canadian collector would engage with his hockey card collection every day for three or more hours!

The time devoted by some to playing video games speaks to their immersive qualities. We have shown that role playing games (RPGs) lead to greater flow experiences than arcade type video games (Larche et al., 2020). Thus, something about the 'alternate world' of the RPG games heightens this immersion. The fact that a significant number of teens are playing these games for three hours or more per day shows how invested they may be in these alternate worlds. For the non-gamer, the thought of spending money on a loot box that contains cosmetic items seems ludicrous. For those immersed in the world of the game for hours on end, the appeal is more transparent. In Zendle's study, 15.3\% of adolescents reported buying loot boxes to change the way that the characters or other things they control look. These individuals conveyed the teenage angst related to fitting in with other players: 'There's too much incentive to do so. Once you get better at the game, everyone else at your skill level has more and more expensive skins, prompting me to buy more and more to fit in.' Others seek to look different, look unique or look good - a kind of status motive. They buy them to 'show off' to other players.

One important difference between the card collecting analogy and loot boxes involves a sense of agency. While a rare hockey card may complete a set, there is no sense in which the rare card becomes part of purchaser's persona. By contrast, in the immersive games in which loot boxes appear, the skins within the loot box become an integral part of the player's avatar which may elevate the group status of the player, and in turn elevate the reward associated with game play. This may be of special import for those who play to escape - they escape to a world where they have status and respect - a contrast to the real world where they may be struggling. 


\section{Critical Gambling Studies Blog}

In sum, our reading of the literature suggests that loot boxes and slot machines reveal more similarities than differences. While loot boxes always give the player something, so too do slot machine LDWs and bonus features. Like slot machine outcomes, they are randomly determined, and have a reinforcement schedule in which low-value items are more common than the rarest coveted items. The effects on the players are eerily similar to slot machines with the rarest items being more rewarding, arousing and urge inducing than the more common items. Finally, the propensity to buy loot box items is linked to gambling problems with the association strength being especially high (i.e., problematic) among adolescents. Aside from their gambling-like nature, loot boxes may also be theoretically problematic for those who use gaming to escape.

Mike Dixon is a full professor of psychology at the University of Waterloo. He has been continuously funded by Natural Sciences and Engineering Research Council since 1997 and has also received grants from the Heart and Stroke foundation of Canada, the Alzheimer's Society of Canada, and the Ontario Problem Gambling Research Centre. He has published over 100 articles in journals such as Nature, Addiction, Journal of Cognitive Neuroscience, Cognitive Neuropsychology and Cortex.

Chanel Larche is a PhD Candidate in Psychology (Cognitive Neuroscience) at the University of Waterloo. Her Master's and PhD work explores the role of flow experience in problematic gaming and gambling behaviour, as well as the convergence of gambling and video-game modalities in general (e.g., the introduction of gambling features into certain video-games, and the gamification of gambling games). Her work aims to determine the implications such convergences have on a player's psychophysiological experience and problematic gambling and gaming behaviour. This work has received funding from the funded by Natural Sciences and Engineering Research Council, Gambling Research Exchange Ontario, and Fonds de Recherche du Québec (Nature et technologies).

\section{$\underline{\text { References }}$}

Brown, R. I. (1986). Arousal and sensation-seeking components in the general explanation of gambling and gambling addictions. International Journal of the Addictions, 21(9-10), 1001-

1016. https://doi.org/10.3109/10826088609077251

Delfabbro, P., King, D.L., Browne, M., et al. (2020). Do EGMs have a stronger association with problem gambling than racing and casino table games? Evidence from a decade of Australian prevalence studies. Journal of Gambling Studies 36, 499-511. https://doi.org/10.1007/s10899-020-09950-5

Dixon, M.J., Stange, M., Larche, C., Graydon, C., Fugelsang, J., \& Harrigan, K. (2018). Dark flow, depression, and multiline slot machine play. Journal of Gambling Studies, 34(1), 73-84. 


\section{Critical Gambling Studies Blog}

Dixon, M.J., Gutierrez, J., Larche, C.J., Stange, M., Graydon, C.M., Kruger, T.B., Smith S.D. (2019). Reward reactivity and dark flow in slot-machine gambling: "Light" and "dark" routes to enjoyment. Journal of Behavioural Addictions, 8, 489-498. DOI: 101556/2006.8.2019.38

Griffiths, M.D. (2018). Is the buying of loot boxes in video games a form of gambling or gaming? Gaming Law Review, 52-54. http://doi.org/10.1089/glr2.2018.2216

Harrigan, K. A., \& Dixon, M. (2009). PAR Sheets, probabilities, and slot machine play: Implications for problem and non-problem gambling. Journal of Gambling Issues, 23, 81-110.

http://dx.doi.org/10.4309/jgi.2009.23.5

Kristiansen, S. \& Severin, M. C. (2020). Loot box engagement and problem gambling among adolescent gamers: Findings from a national survey. Addictive Behaviors, 103, 106254.

https://doi.org/10.1016/j.addbeh.2019.106254

Larche, C.J, Chini, K., Lee, C. Dixon, M.J., \& Fernandes M. (2019). Rare loot box rewards trigger larger arousal and reward responses, and greater urge to open more loot boxes. Journal of Gambling Studies, online first. https://doi.org/10.1007/s10899-019-09913-5.

Larche, C. J., Tran, P., Dhaliwal, N., Kruger, T. B., Dixon, M. J. (2021). Escaping the woes through flow? Exploring the relationship between gaming to escape, depression and flow in role-playing games and platform games [Special Issue: The Converging Worlds of Gambling and Video Gaming]. Journal of Gambling Issues, 46, 151-181. http://dx.doi.org/10.4309/jgi.2021.46.9

Zendle, D. \& Cairns. P. (2018). Video game loot boxes are linked to problem gambling: results of a largescale survey. PLoS ONE 13 (11), e0206767. https://doi.org/10.1371/journal.pone.0206767

Zendle, D., Ballou, N., \& Meyer, R. (2019). The changing face of desktop video game monetisation: An exploration of trends in loot boxes, pay to win, and cosmetic microtransactions in the most-played Steam games of 2010-2019. PsyArXiv. https://doi.org/10.31234/osf.io/u35kt

Zendle, D., Meyer, R. \& Over, H. (2019). Adolescents and loot boxes: links with problem gambling and motivations for purchase. Royal Society Open Science, 6, 190049. https://doi.org/10.1098/rsos.190049 